\title{
Video analysis of response of reinforced concrete beam to impact loading during drop test
}

\author{
Filip Hokes ${ }^{1 *}$, Jiri Kala ${ }^{1}$ and Ivan Nemec ${ }^{2}$ \\ ${ }^{1}$ Brno University of Technology, Institute of Structural Mechanics, 60200 Brno, Veveri 331/95, \\ Czech Republic \\ ${ }^{2}$ FEM Consulting, s.r.o., 60200 Brno, Veveri 331/95, Czech Republic
}

\begin{abstract}
A response of concrete and reinforced concrete structures to very rapid dynamic loading shows an increase of both tensile and compressive strength. This behaviour is also accompanied by an increase of stiffness of the structure. Described response can be numerically simulated only with adequate viscous nonlinear material model of concrete. The problem of these simulations is based not only on a necessity of a derivation of the right material model but also on viscous parameters whose values are not known in advance. The proposed article deals with experimental research of the response of the reinforced concrete beam exposed to impact loading during drop test. The beam response was measured with conventional strain gauges and accelerometers and whole experiment was recorded with 1000 frames per second by slow motion camera. Measured values of vertical acceleration were then compared with results of software analysis of slow-motion video footage. The paper contains the description of the experimental research, the comparison of conventional measurements with video analysis and the simulated response of the specimen in the software based on the finite element method using the viscous material model of concrete.
\end{abstract}

\section{Introduction}

Capabilities of today's computers and computational software allow engineers to solve very complex problems with high amount of accuracy in relatively short period of time. Typical example of this situation is the nonlinear simulation of impact loading of civil structures using finite element method. The nonlinear simulation offers engineers quite cheap advantage to design the structure compared with full scale experiment if they are ever feasible. Although it seems that the computer simulation represents great solution of such problems, it often suffers from occurrence of internal parameters that are not known in advance $[8,9]$. From this point of view it is necessary to step back and prepare suitable laboratory or field experiment that can provide values of unknown parameters.

\footnotetext{
* Corresponding author: filip.hokes@ vut.cz
} 
Example of such numerical analysis was published in [1] where design of a concrete road safety barrier had been solved using finite element computational system LS-Dyna [2]. Another example is represented by paper from Němec et al. [3] which deals with nuclear power plant containment damage caused by impact of a plane. All of these examples show nonlinear numerical simulations with use of complex material models and contact algorithms [13]. The right choice of the material model is fundamental to obtain realistic numerical results. In case of concrete civil structures, the response of concrete to rapid dynamic loading shows an increase of both tensile and compressive strength which implies the use of adequate viscous nonlinear material. The viscous formulation of concrete material models for rapid dynamic loading can be implemented in terms of Perzyna approach [3] or in terms of Duvaut-Lions approach [3]. The enhancement of standard nonlinear material models based on theory of plasticity or models based on damage theory with Duvaut-Lions regularization is using viscosity parameter. Values of this parameter differ with strain rates and although its values are recommended by CEB-FIB standards [5], it was necessary to prove them by experiment $[7,10]$.

One possible way to identify values of viscosity for concrete is represented by measurement of the response of a concrete beam exposed to impact loading during drop test $[11,12]$. The goal of this article is thus exhibition of performed drop test on the reinforced concrete beam. The article deals with description of test configuration, used measuring techniques and last but not least with image processing analysis of footage captured with slow-motion camera which had provided valuable information about the behaviour of the beam.

\section{Description of the drop test}

Due to the possibilities, the experiment was performed as a field test. The design of size and choice of the material for the typical specimen was affected by available battering ram weight with value of $500 \mathrm{~kg}$ and requirement of carrying it by four man in hands. Specimens with height of $250 \mathrm{~mm}$, width of $120 \mathrm{~mm}$ and length of $1700 \mathrm{~mm}$ were casted from concrete grade $\mathrm{C} 30 / 37$. The reinforcement was formed by 4 longitudinal steel bars of grade B500B with diameter of $10 \mathrm{~mm}$ and stirrups with diameter of $6 \mathrm{~mm}$. In order to requirement of manual handling, supports were made from 9 nine hard wood beams with height of $100 \mathrm{~mm}$, width of $100 \mathrm{~mm}$ and length of $1000 \mathrm{~mm}$. Supports were provided with stops for precise mounting of the beam. The beam was also modified for manual handling with 2 transversal steel bars at both ends. The form of the placing the beam in the drop test device is depicted in Fig. 1.
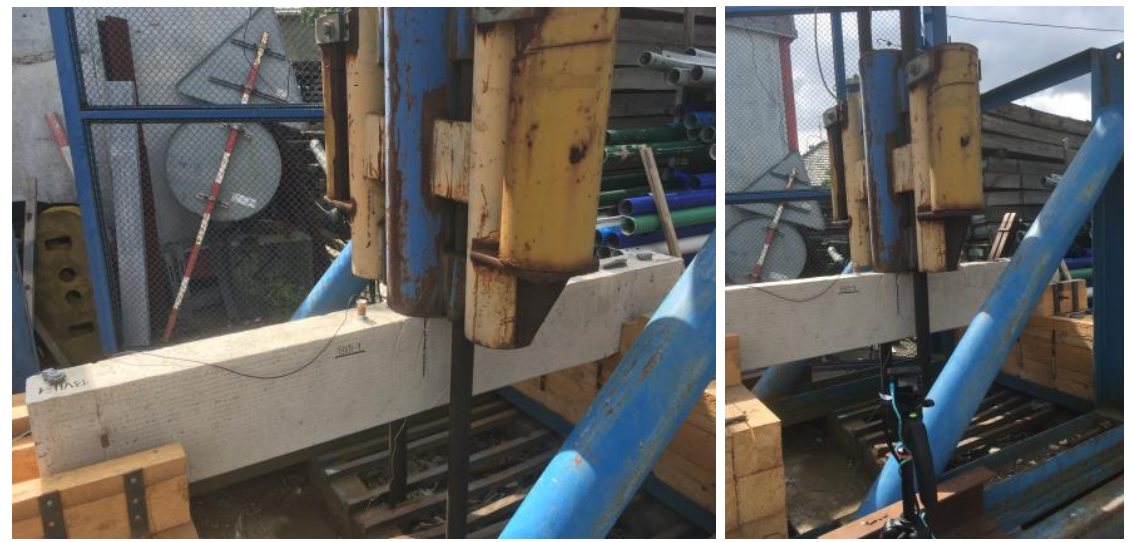

Fig. 1. The beam, supports and the battering ram. 


\subsection{Configuration of the experiment}

The specimen was placed within the drop test device as a simply supported beam. The span was limited with dimensions of the device and was so of value $1240 \mathrm{~mm}$. The length of the contact area was designed with value of $230 \mathrm{~mm}$. The height of the lower surface of the beam above the ground surface was $300 \mathrm{~mm}$. The graphical visualisation of testing configuration with all important details is illustrated on Fig. 2.

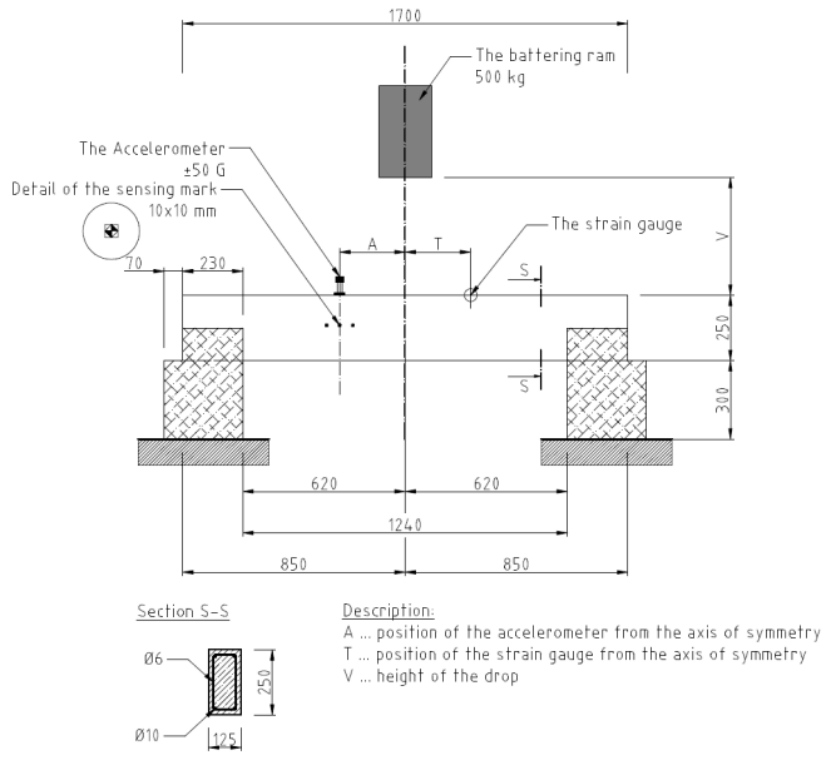

Fig. 2. Configuration of the experiment.

\subsection{Instrumentation}

The measuring of the response of the reinforced concrete beam was performed both with conventional strain gauges and accelerometers. Whole experiment was also captured with slow-motion camera that is able to record with 1000 frames per second. The position of the accelerometer with range of $\pm 50 \mathrm{G}$ and the position of strain gauges is depicted in detail in Fig. 2. The front optical element of the camera was placed $1000 \mathrm{~mm}$ in front the surface of the beam where special sensing marks were attached. These marks were design in order to get relatively high contrast and precise scale for the video analysis in Kinovea software [6]. Detail of these marks with dimensions are also depicted in Fig. 2. The measurement was performed with use of 8 channel measuring switchboard provided with the analogue USBAD16f data acquisition system. The measurement recording and evaluation was done in NextView 4.0 software.

\subsection{Course of the experiment}

Drop tests were performed on 12 beams in total during the year 2018. The measurement were divided into 2 days. The division into 2 parts helped us to identify some specific problems that should be fixed within following measurement. Each beam was exposed to 2 drops. The first drop, which was always performed from lower height, represented main measurement while the second drop was used for checking all measuring instruments. The 
final drop of the first measuring day was performed from height of $800 \mathrm{~mm}$ above the top surface of the beam and it caused total destruction of the specimen.

\section{Specifics of the heavy-weight drop test and their solution}

As mentioned above, the weight of battering ram was approximately $500 \mathrm{~kg}$. The impact of a such heavy-weight body caused by drop from a height up to $1.0 \mathrm{~m}$ is generally an action lasting only fractions of the second and thus it is impossible to observe the behaviour of the specimen and measuring sensors. The length of the test time period was the main reason, why it was decided to record a process of experiment with the slow-motion camera. This decision had made it very advantageous because slow-motion footage showed us the essential problem with the attachment of accelerometers. Accelerometers are usually attached to the surface of a specimen with the use of magnet and nut bolt washer, which is directly bonded to the surface using epoxy resin adhesive. This way of the connection showed up as insufficient because as you can see in fig. 3, the sensor was detached from the washer.
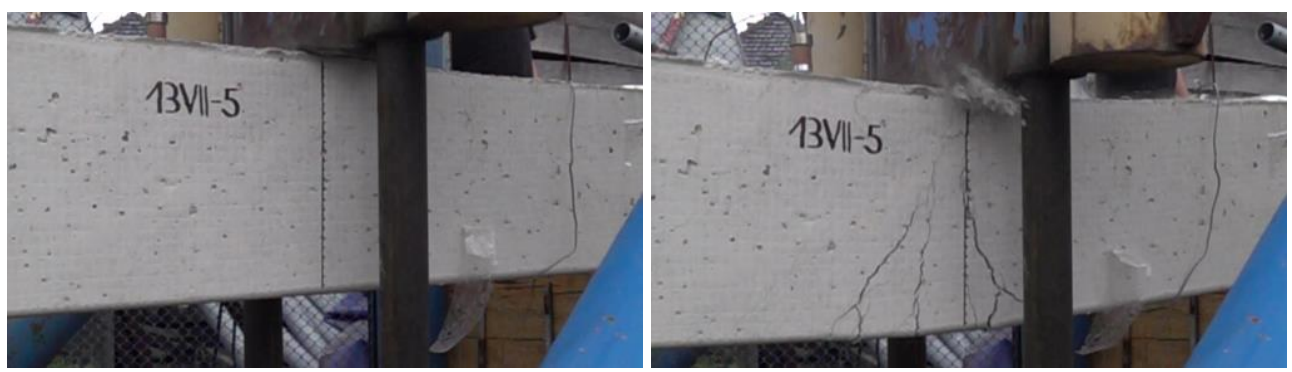

Fig. 3. Position of the accelerometer before and at $0.014 \mathrm{~s}$ after the impact of the weight.

When viewing slow-motion video, it was also found that the resolution of the footage is large enough for additional software processing and calculation of the vertical displacement and vertical acceleration of the specimen over time with utilization of the Kinovea software. The first analysis of the displacement was performed with scale that was drawn on the front surface of the beam by hand. This approach was not only inaccurate but results were also distorted by flying fragments of the concrete. Described distorted results that was exported from the Kinovea software are graphically illustrated in fig. 4. The solution of this problem was easily achieved with stickers on which the sensing marks were printed. The graphical form of these sensing marks are illustrated in fig. 2.

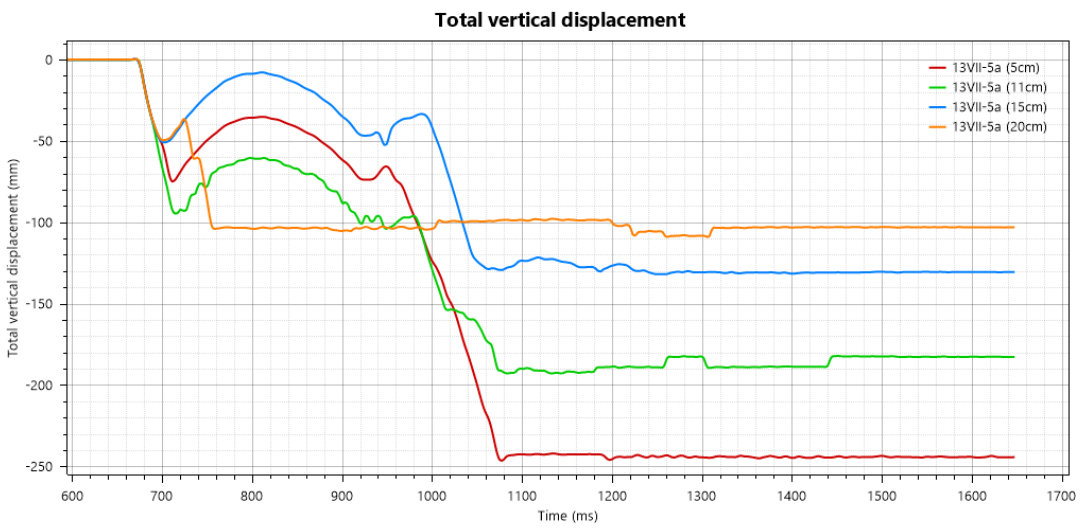

Fig. 4. Distortion of results by flying fragments of the concrete. 


\section{Results}

All of above described problems that had occurred during the first measuring day were satisfactorily improved within the second measurement. The typical result of timedisplacement diagram that was obtained from slow-motion footage targeted at sensing marks on the front surface of the specimen is illustrated in fig. 5. The described diagram shows the maximum amplitude of the displacement for drop of the battering ram from the height of $750 \mathrm{~mm}$.

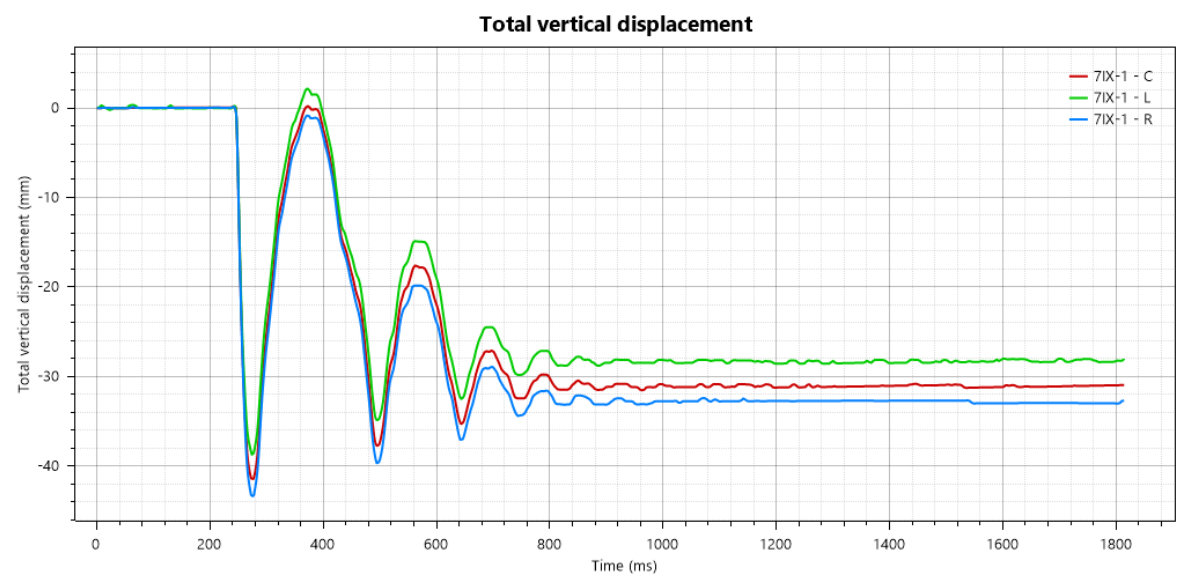

Fig. 5. The typical result of time-displacement diagram for the specimen with the sensing mark.

Results of vertical displacement over time can be considered relatively accurate because the final deformation of the specimen corresponded to residual vertical displacement that is depicted in fig. 5.

A problem with an accuracy of results were found in case of vertical acceleration calculated with the Kinovea from the slow-motion footage (fig. 6). These results are in comparison with computations in LS-Dyna and also in comparison with measurements using accelerometers different in magnitudes. The authors suppose that the used frame rate of 1000 FPS and the resolution is not enough for this kind of analysis.

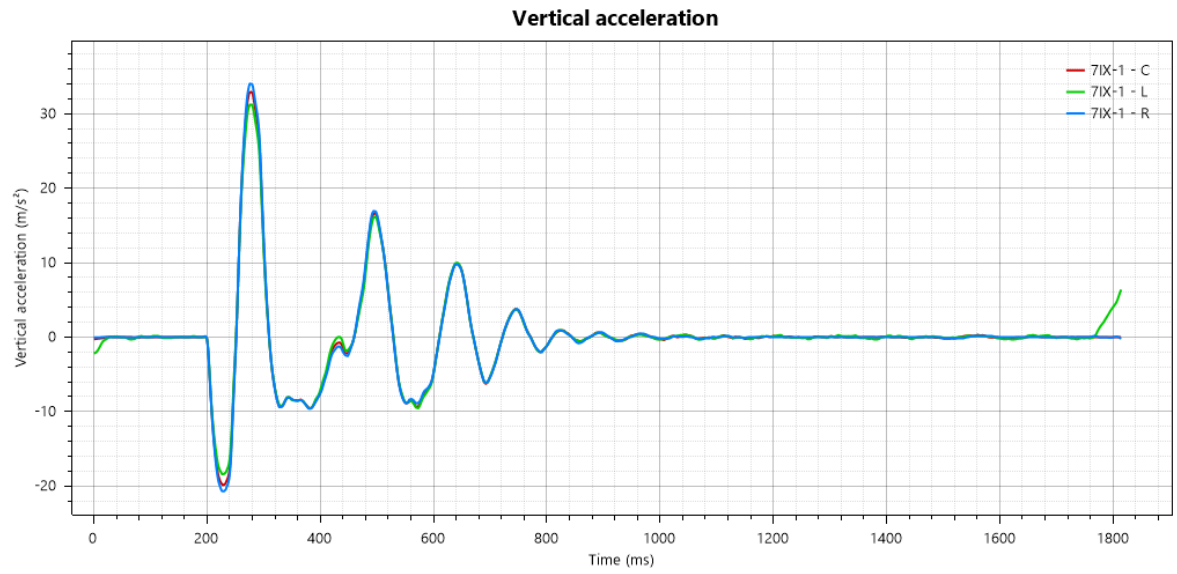

Fig. 6. The typical result of time - acceleration diagram for the specimen with the sensing mark. 


\section{Conclusion}

Results of described analysis of slow-motion footage captured during drop test experiment on the reinforced concrete beam revealed this kind of analysis as a possibility to standard measuring techniques. As it was showed up, it can perform not only as tool for watching at actions that last for very short period of time but also as complementary measurement.

Financial support of the Ministry of Education, Youth and Sports of the Czech Republic within project No. LO1408 AdMaS UP awarded under "National Sustainability Programme I" and support of Czech Science Agency within project no. GACR 17-23578S "Damage assessment identification for reinforced concrete subjected to extreme loading" are gratefully acknowledged. Results presented in this paper are direct outcome of the specific collaboration agreement between the FEM Consulting s.r.o. and the Brno University of Technology, Faculty of Civil Engineering.

\section{References}

1. P. Hradil, J. Kala, V. Salajka, Safety and Reliability: Methodology and Applications Proceedings of the European Safety and Reliability Conference, ESREL 2014 (2015)

2. Livermore Software Technology Corporation (LSTC), LS-DYNA Theory Manual (2014)

3. I. Němec, Š. Sychrová, Applied Mech. (2013)

4. J.C. Simo, T. J. R. Hughes, Computational inelasticity (1998)

5. CEB (Comite'Euro-International du Beton), CEB-FIPModel Code 1990 (1990)

6. J. Charmant, Kinovea : www.kinovea.org (2019)

7. M. Hušek, P. Král, J. Kala, P. Hradil, P. Maňas, Advances in Military Technology, 13 (1), pp. 107-118. (2018)

8. P. Král, P. Hradil, J. Kala, Computers and Concrete, 22 (2), pp. 227-237. (2018)

9. M. Hušek, J. Kala, P. Král, F. Hokeš, IOP Conference Series: Materials Science and Engineering, 245 (3), art. no. 032070, (2017)

10. F. Hokes, J. Kala, Frattura ed Integrita Strutturale, 11 (39), pp. 7-16, (2017)

11. P. Kral, P. Hradil, J. Kala, F. Hokes, M. Husek, Procedia Engineering, 172, pp. 578585. (2017)

12. Z. Kala, International Journal of Mechanics, 12, pp. 121-130. (2018)

13. Kala, Z. MATEC Web of Conferences, 76, art. no. 04026, (2016) 